\title{
LIMBAL AUTOTRANSPLANTATION IN THE ACUTE AND CHRONIC PHASES OF SEVERE CHEMICAL INJURIES
}

\author{
STEPHEN MORGAN AND AIDAN MURRAY \\ Sunderland
}

\begin{abstract}
SUMMARY
We present the results of six cases of severe chemical burn of the eye treated by limbal autotransplantation. Three cases were treated in the acute phase, and three in the chronically scarred, healed phase. In five of the six cases, the stability of the ocular surface was markedly improved, resulting in two of the three acute cases in full recovery of normal vision, and in the three chronic cases in improved comfort and reduced corneal opacity and vascularity. In two chronic cases, visual acuity was improved and in one, limbal autotransplantation was followed by successful penetrating keratoplasty. Limbal autotransplantation is a valuable procedure in the rehabilitation of the unilateral, severely chemically burned eye. The indications, techniques, complications and results of this procedure are discussed.
\end{abstract}

A major cause of severe visual loss following ocular chemical burns is damage to the ocular surface structures, notably the cornea. ${ }^{1-3}$ The most severely burned eyes have global loss of epithelial structures, corneal opacity, profound anterior segment ischaemia and extensive damage to intraocular structures including cataract and secondary glaucoma. These eyes often progress of corneal perforation and eventual loss of the eye. However, there are a large number of cases in which slightly less severe injury may still lead to major visual loss secondary to damage to the ocular surface. Such eyes show prolonged healing and re-epithelialisation, thickening, opacification and vascularisation of the corneal epithelium, vortex or punctate keratopathy and stromal opacification. Kenyon and $\mathrm{Tseng}^{4}$ have postulated that this state of 'ocular surface failure'

Correspondence to: Mr Stephen J. Morgan, DO, FRCSEd, FRCOphth, Corneal Diseases and Excimer Laser Unit, Sunderland Eye Infirmary, Queen Alexandra Road, Sunderland SR2 9HP, UK. is due to the loss of a significant proportion of the stem cells in the limbal corneal epithelium.

Kenyon and Tseng proposed repopulation of the limbal stem cells by 'limbal autograft transplantation' (LAT), and in 1989 reported a series of 26 eyes treated by this technique, ${ }^{4}$ which we refer to here as 'limbal autotransplantation'. Other small series of the results of LAT in various clinical situations have also been reported. ${ }^{5-8}$

The optimum timing of LAT after chemical injury has yet to be determined. However, logically there would appear to be at least two 'windows of opportunity'. Accurate grading of chemical burns according to the system of Pfister and $\mathrm{Koski}^{3}$ or Roper-Hall ${ }^{1}$ enables one to give a prognosis based upon the likely response of the injury to medical therapy. This study has used the Roper-Hall system (Table I). Eyes in the poor prognosis group (RoperHall grade III or worse) are possible candidates for autografting. The first 'window of opportunity' occurs in the acute phase after the injury, when there has been sufficient revascularisation of the ischaemic limbus to possibly support a limbal autograft. The second 'window' falls when the eye is in a chronically scarred, healed phase. The objective of grafting in the first 'window' is to prevent permanent sequelae from developing, and in the second 'window' is firstly to treat ocular irritability and secondly as a part of a management plan to 'rehabilitate' the eye, a process which as in our case 4 may include the eventual performance of a penetrating keratoplasty. We report our experience of the application of these principles to the management of six severely chemically burned eyes.

\section{PATIENTS AND METHODS}

All patients were under the care of one of us (S.M.). All patients presenting with grade III or worse chemical burns affecting principally one eye were eligible for inclusion in the study. Patients with a 
Table I. Classification of degree of severity of ocular chemical burns

\begin{tabular}{lllll}
\hline Grade & Corneal haze & Epithelium & Limbal ischaemia & Prognosis \\
\hline I & Nil & Subtotal loss & Nil & Full recovery \\
II & Mild to moderate & Subtotal loss & $<1 / 3$ & Recovery, minor scarring \\
III & Iris details obscured & Total loss & $1 / 3$ to $1 / 2$ & Significant visual loss \\
IV & Opaque & Total loss & $>1 / 2$ & Risk of loss of eye \\
\hline
\end{tabular}

Modified after Roper-Hall. ${ }^{1}$

chemical burn greater than grade I in the fellow eye were not considered. Four eligible patients presented acutely during the course of the study, of whom three formed the 'acute' group and one entered the 'chronic' group. Two other patients with long-term sequelae of old chemical burns certainly of at least grade III presented during the study period and entered the 'chronic' group.

Medical management of the acute injury followed current conventional practice, with copious ocular lavage and removal of foreign bodies, early intensive application of topical steroids tailed down after the first 7-10 days of treatment, application of topical vitamin $\mathrm{C}$, and use of mydriatics and prophylactic antibiotics. All topical treatment in the acute phase was with preservation-free drop preparations.

All LAT procedures were carried out under general anaesthetic. Starting with the recipient eye, the corneal epithelium (if present) was debrided to beyond the surgical limbus. In chronic cases, a superificial keratectomy was performed to remove superficial pannus, calcification and other superficial opacities. A conjunctival peritomy was then performed, and the conjunctiva recessed to $2-3 \mathrm{~mm}$ behind the surgical limbus, where it was secured to the episclera with interrupted 8/0 Vicryl sutures. In 5 of the 6 cases, the full $360^{\circ}$ of limbal conjunctiva was recessed (see below).

Limbal grafts were then harvested from the donor eye. The graft excision sites were determined by the

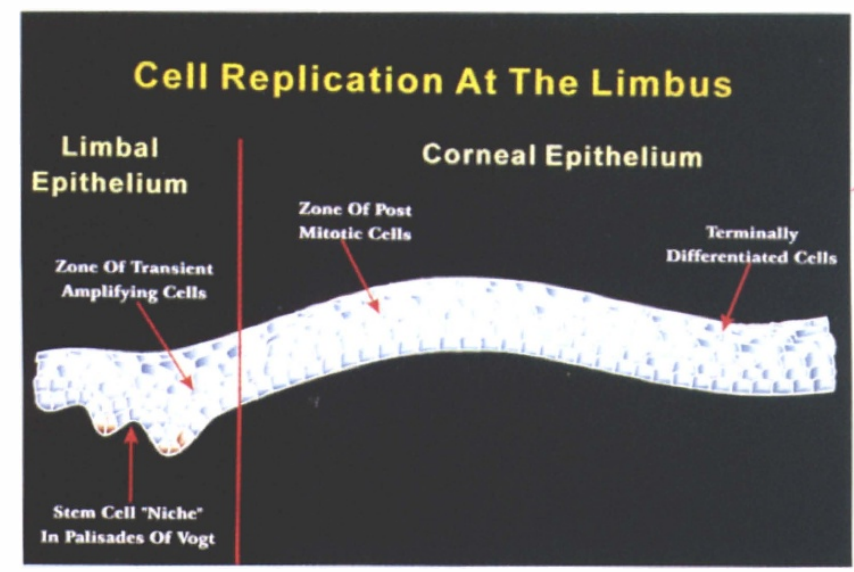

(a) presumed location of limbal epithelial stem cells, in the basal epithelium within the palisades of Vogt (Fig. 1). The grafts were between 2 and 3 clock-hours in length, and taken from the 12 o'clock and 6 o'clock positions. (In one case, the two grafts were taken at separate surgical procedures: see below.) A blade was used to create a partial-thickness corneal groove incision central to the limbal vascular arcades and the incision was then carried back into the limbus in lamellar fashion. Vannas' scissors were used to define and free a fringe of conjunctiva $1-2 \mathrm{~mm}$ in width and attached to the piece of cornea. The graft's deep attachments at the limbus were then divided and the graft was immediately transferred to the recipient eye. When correct orientation of the graft had been established, it was secured in position with interrupted 10/0 monofilament nylon sutures placed partial thickness in the recipient cornea.

In some cases, the donor sites were closed with interrupted 8/0 Vicryl sutures; in others they were left open and covered with a bandage contact lens. In all cases a $21 \mathrm{~mm}$ high water content therapeutic contact lens was applied to the recipient eye. Preservative-free topical antibiotics were applied. Eye pads were not used.

Post-operatively, the therapeutic contact lens was removed when the host cornea had epithelialised (at about 1 week in all cases) and treatment with preservative-free antibiotics was stopped. Low doses of preservative-free topical prednisolone

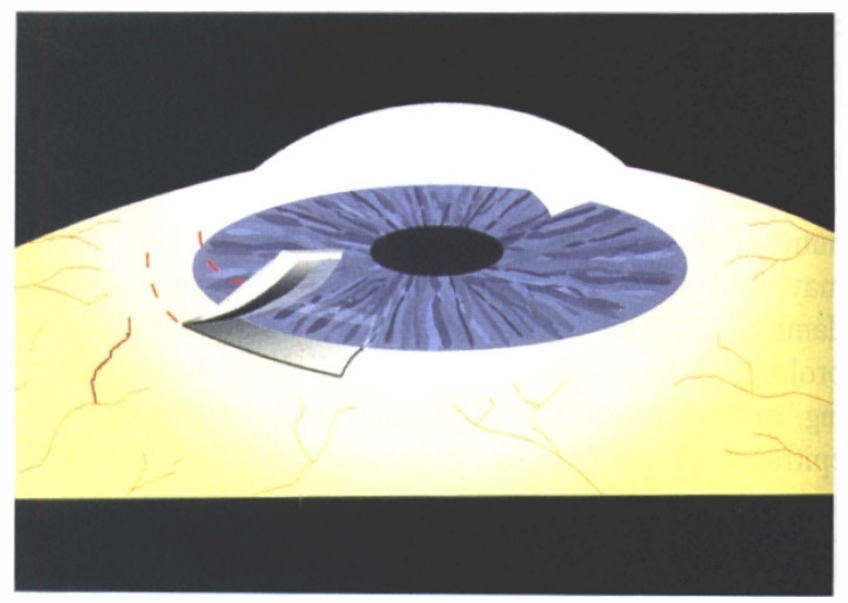

(b)

Fig. 1. (a) Diagram of the limbal corneal epithelium, to show the presumed location of the stem cells in the palisades of Vogt. The proposed sites of the transient amplifying and post-mitotic cells are conjectural. (b) Diagram to show the size and position of a graft being harvested. 
Table II. Clinical features and management of acute group

\begin{tabular}{lccccccc}
\hline Case no. & Age/sex Grade of injury & $\begin{array}{c}\text { Time following } \\
\text { injury }\end{array}$ & No. of grafts & $\begin{array}{c}\text { Follow-up time } \\
\text { (months) }\end{array}$ & Final VA & Comment \\
\hline 1 & $23 \mathrm{M}$ & IV & $6 / 52$ & 2 & 12 & $6 / 6$ & Clear cornea \\
2 & 19 M & IV & $11 / 7$ & 2 & 8 & $6 / 9$ & Minimal scarring \\
3 & $43 \mathrm{M}$ & IV & $3 / 52$ & $1+1(5$ weeks later $)$ & 18 & CF & Hypotony, vascularised cornea \\
\hline
\end{tabular}

$0.5 \%$ were tailed off over the next few weeks. Corneal sutures were removed if they loosened, and all sutures were removed before discharge from follow-up.

\section{Acute Group}

\section{RESULTS}

Three patients formed the acute group. In all three cases, LAT was carried out when the limbus of the injured eye had revascularised sufficiently to support a graft. The clinical features and management of these patients are summarised in Table II.

\section{Case 1}

A 23-year-old man sustained a grade IV ammonia burn to his left eye as a result of an assault. His right eye, which escaped injury was amblyopic, with a best corrected acuity of 6/60. Despite treatment with steriods and ascorbic acid, the left eye showed very slow re-epithelialisation with invasion of conjunctival-type epithelium, progressive neovascularisation of the cornea and the development of pseudopterygia. At 6 weeks following injury, two limbal autografts were performed from the right to the left eye. The left cornea re-epithelialised within 8 days. The donor eye healed without sequelae. The patient reported rapid improvement in vision in the injured eye. At 8 months post-operatively the recipient ocular surface was smooth and stable, with no corneal vascularisation or scarring, and an unaided acuity of $6 / 6$ (Fig. 2). The donor ocular surface was also normal.

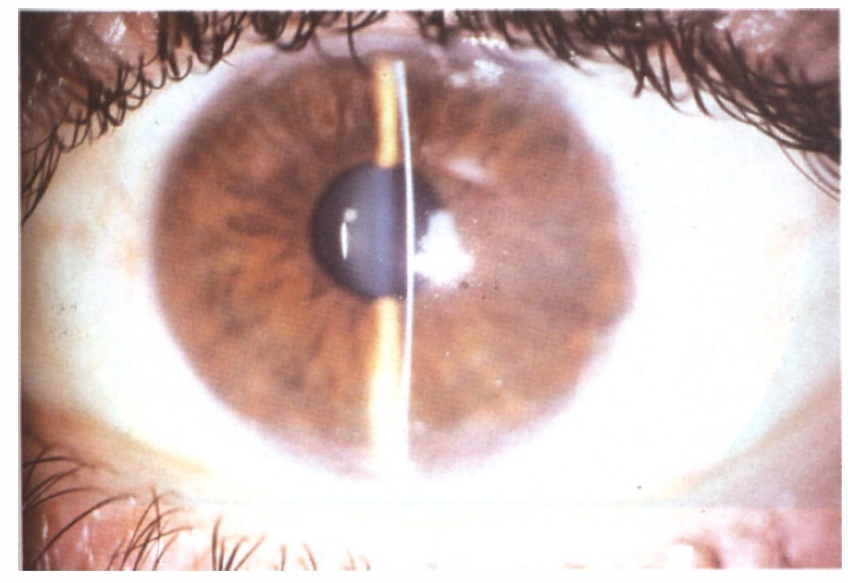

Fig. 2. Case 1. Grade IV injury, 8 months after LAT. Acuity was $6 / 6$ unaided.
Case 2

A 19-year-old man sustained a grade IV ammonia burn to his right eye as a result of an assault. His left eye, which sustained a grade I injury, was amblyopic, with a best corrected acuity of 6/36. At 11 days following injury, the cornea remained virtually totally de-epithelialised, although the limbus showed revascularisation. Two limbal autografts were performed from the left to the right eye. The right cornea re-epithelialised in 5 days. The donor eye healed without sequelae. The right cornea showed transient partial $(20 \%)$ coverage with epithelium that clinically resembled conjunctival epithelium at the nasal side, but this regressed completely within 6 months. At 8 months post-operatively the ocular surface was smooth and stable. There was minor non-progressive superficial vascularisation in the inferonasal quadrant and minor stromal scarring. The patient's unaided acuity was 6/9, which he reported to be equal to his acuity prior to the injury. The donor ocular surface remained normal.

\section{Case 3}

A 43-year-old man received a face full of concentrated acidic kettle descaler following a crime of passion. He sustained extensive superficial skin burns of the face, a grade IV chemical injury to the left eye and a grade I injury to the right eye. The right eye was mildly amblyopic, with a best corrected acuity of $6 / 12$. The acute management was made more challenging when the patient developed delirium tremens due to alcohol withdrawal and temporarily discharged himself from hospital. At 3 weeks following injury the inferior $180^{\circ}$ of the limbus of the left eye remained severely ischaemic although the upper limbus had revascularised. A large corneal epithelial defect persisted. The pupil was noted to be slightly eccentric. A single large limbal autograft was performed from the 12 o'clock position of the right eye to the corresponding position in the left eye. The cornea re-epithelialised in 1 week but by 8 weeks had become re-invaded by epithelium having the clinical characteristics of conjunctival epithelium. A second limbal autograft was performed from the 6 o'clock position of the right to the left eye. The donor eye healed without sequelae. The recipient eye developed recurrent corneal epithelial defects, progressive corneal vascularisation, severe hypotony and inferior displacement of the pupil. A temporary tarsorrhaphy was performed and later re-opened. At 18 months 
Table III. Clinical features and management of chronic group

\begin{tabular}{|c|c|c|c|c|c|c|c|c|c|}
\hline Case no. & Age/sex & $\begin{array}{l}\text { Grade of } \\
\text { injury }\end{array}$ & $\begin{array}{l}\text { Time following } \\
\text { injury }\end{array}$ & $\begin{array}{l}\text { Clinical } \\
\text { problem }\end{array}$ & $\begin{array}{l}\text { Initial } \\
\text { VA }\end{array}$ & $\begin{array}{l}\text { No. of } \\
\text { grafts }\end{array}$ & $\begin{array}{l}\text { Follow-up } \\
\text { time }\end{array}$ & Final VA & Comment \\
\hline 1 & $47 \mathrm{M}$ & IV & 12 months & $\begin{array}{l}\text { Vascularised } \\
\text { decomp. } \\
\text { cornea }\end{array}$ & $\mathrm{CF}$ & 2 & 2 years & $6 / 18$ & $\begin{array}{l}\text { PK done } \\
3 \text { months } \\
\text { later }\end{array}$ \\
\hline 2 & $25 \mathrm{M}$ & ? III & 8 years & $\begin{array}{l}\text { Vascularised, } \\
\text { scarred, } \\
\text { irritable }\end{array}$ & $6 / 24$ & 2 & 4 months & $6 / 6$ & $\begin{array}{l}\text { Comfortable; } \\
\text { stable }\end{array}$ \\
\hline 3 & $37 \mathrm{M}$ & IV & 9 years & $\begin{array}{l}\text { Vascularised, } \\
\text { scarred, } \\
\text { irritable }\end{array}$ & $\mathrm{CF}$ & 2 & 3 months & $3 / 60$ & $\begin{array}{l}\text { Comfortable; } \\
\text { patient died }\end{array}$ \\
\hline
\end{tabular}

PK, penetrating keratoplasty.

following injury the eye was comfortable, with an extensively vascularised cornea, moderate stromal scarring and an acuity of counting fingers. The donor ocular surface remained normal.

\section{Chronic Group}

There were three patients in the chronic group. In all three cases, LAT was performed on eyes that had reached the healed, scarred, inactive stage following chemical burns sustained a year or more previously. In all three cases the patients complained of irritation and of poor acuity. In one case, LAT formed part of a staged reconstruction involving penetrating keratoplasty. The clinical features and management are summarised in Table III.

\section{Case 4}

A 47-year-old man sustained a grade IV lime burn of his left eye and a grade I burn of the right eye in an industrial accident (Fig. 3). The right eye, which had previously been normal and healthy, recovered without sequelae. Re-epithelialisation of the left cornea and reperfusion of the ischaemic areas took in excess of 3 months. At 6 months a symblepharon causing painful restriction of his eye movements was

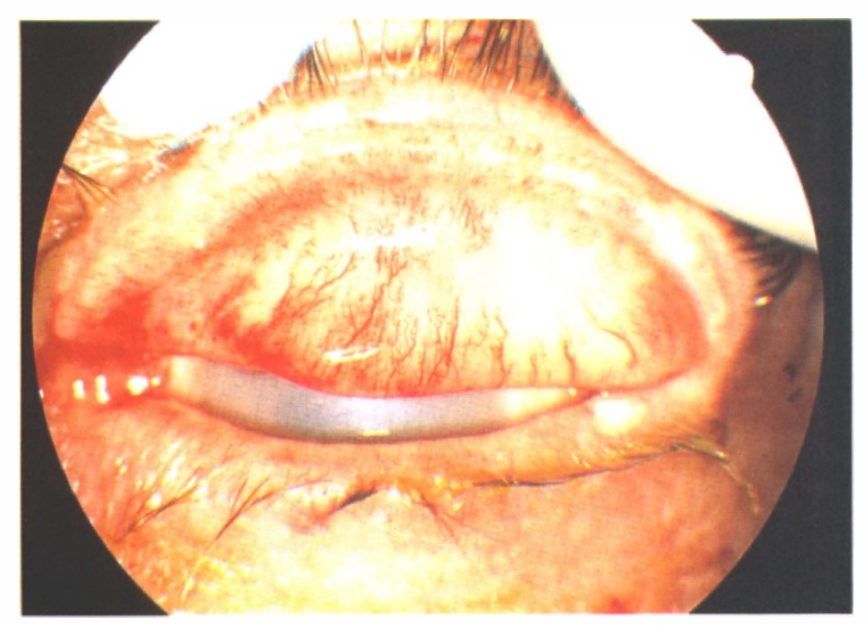

(a) freed surgically followed by the use of a symblepharon ring. At 1 year following injury his left eye was severely irritable with bullous keratopathy, corneal vascularisation and pannus, and normal intraocular pressure. He underwent two simultaneous right to left autografts, together with superficial keratectomy and removal of vascular pannus. The left eye re-epithelialised in 1 week and showed much reduced corneal vascularisation. Three months later a tissue-matched penetrating keratoplasty was performed on the left eye. At 2 years following keratoplasty the left eye was white and quiet, with a perfectly clear corneal graft with no vascularisation and a healthy surface (Fig. 4). There had been no signs of rejection at any stage. The acuity was $6 / 18$. $\mathrm{He}$ was on no treatment. The donor eye ocular surface remained normal.

\section{Case 5}

A 25-year-old man was referred because of a chronically irritable left eye. Eight years previously he had suffered a plaster burn to the left eye in a work-related accident; his records showed that this had been of grade III to IV, and that the right eye had escaped injury. Examination showed the left

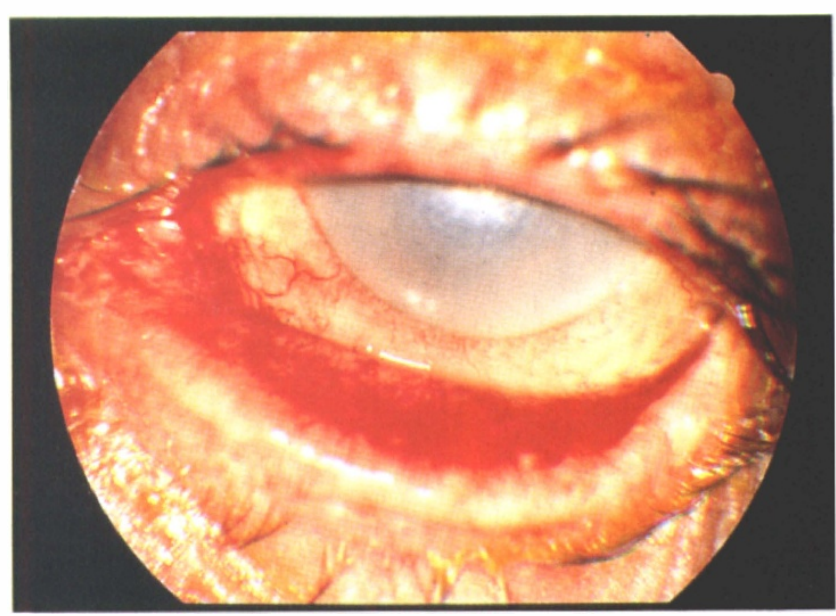

(b)

Fig. 3. Case 4. Grade IV injury, 2 days following injury. (a) Upper tarsal plate, (b) cornea and limbus. Note the marked tissue ischaemia and corneal opacification. 


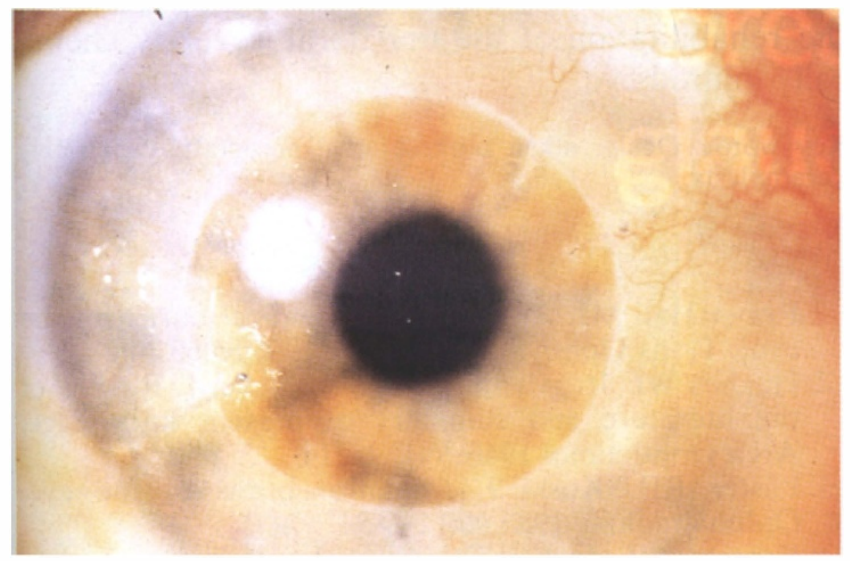

Fig. 4. Case 4. Two years 3 months following LAT and 2 years following penetrating keratoplasty. Acuity was 6/18 unaided.

cornea to be extensively vascularised, with opacities at the level of Bowman's layer and widespread punctate keratopathy. Best corrected acuity was 6/24. The right eye was normal and healthy. He underwent two right to left limbal autografts, and a superficial keratectomy to remove opacities and pannus. One week post-operatively, the recipient eye developed a superficial infection related to the conjunctival sutures, requiring treatment with topıcal antibiotics. The donor eye healed without sequelae. After 4 months the left acuity had improved to $6 / 6$ unaided, the appearance was much improved, and he was discharged from further follow-up. The donor ocular surface remained normal.

\section{Case 6}

A 37-year-old man was referred because of a chronically photophobic, irritable left eye with poor vision. Nine years previously he had suffered a grade IV ammonia burn to his left eye as a result of an assault. His right eye had escaped injury. Examination showed a severely photophobic left eye with an acuity of $3 / 60$. There was extensive scarring, vascularisation and punctate keratopathy. The right eye was normal. Two simultaneous right to left limbal autografts were performed, together with extensive superficial keratectomy and removal of pannus. A microperforation of the donor eye was noted during surgery; this healed without sequelae. The recipient eye re-epithelialised in 1 week, and the patient reported considerable reduction in discomfort and photophobia. His visual acuity did not improve due to extensive stromal opacities. Further treatment was planned in the form of a tissue-matched penetrating keratoplasty, but after 3 months of follow-up he died suddenly from unrelated natural causes.

\section{DISCUSSION}

We have added to the growing body of evidence of favour of limbal autotransplantation to improve the prognosis after severe chemical burns of the eye. Considering our group of three eyes treated in the acute phase, in two of our three cases LAT resulted in restoration of a normal, healthy ocular surface despite alkali burns of grade IV. In the third case, a normal healthy ocular surface was not restored. The clinical impression of this case was that intraocular aspects of this patient's chemical injury (manifested by chronic ocular hypotony and pupillary distortion) would have resulted in a poor visual prognosis in any circumstances. LAT at 11 days following injury (case 2) appears to have been just as effective as at 6 weeks following injury (case 1). While the optimum timing for the procedure has yet to be precisely defined, we would suggest that there is nothing to be gained from further delay when revascularisation of the limbus of such a severely injured eye can be convincingly demonstrated. We would accept that only a randomised prospective trial can answer the question of whether spontaneous improvement might have resulted in cases such as our cases 1 and 2, but our experience suggests that this was most unlikely to occur, and the failure of the pseudopterygia and vascularisation to recur in case 1 following LAT suggests that surgical intervention did indeed alter the outcome. Chemical burns of this severity are, fortunately, relatively rare in our experience.

In our chronic group, the primary objective of LAT was to improve symptoms of irritation and photophobia, with the secondary aim of improving vision, if necessary, by corneal transplantation. The objective was achieved in all cases, and indeed in one (case 5) our expectations were exceeded by an improvement in the patient's acuity from $6 / 24$ to $6 / 6$. The clinical experience of penetrating keratoplasty in eyes such as these is depressing, with a high incidence of corneal revascularisation, rejection and graft failure. ${ }^{9,10}$ Our case 4 , though but a single example, demonstrates the potential for improved prognosis from the use of a staged plan of ocular surface reconstruction by (1) LAT and (2) penetrating keratoplasty.

We were fortunate in that three of our cases, and indeed all the acute group, had a donor eye that was amblyopic. Indeed, it was this happy circumstance that encouraged us to perform LAT for the first time. The occurrence of a donor microperforation (case 6) should remind us that there is a potential for sightthreatening complications in this procedure, although no permanent sequelae occurred in any donor eye in this series, nor was any measurable refractive change induced.

Other authors have reported that where limbal tissue is taken from a donor eye whose limbus is itself compromised, it is possible to induce a state of ocular surface failure in the donor eye.,11 Thus it is important not to undertake LAT in patients who 
have sustained significant injury to the potential donor eye, and not to remove excessive amounts of donor eye limbal tissue under any circumstances. Bearing these considerations in mind, we consider it reasonable to recommend LAT to patients in whom the uninjured eye has normal vision, and in whom the injured eye has a severely guarded prognosis.

With regard to the management of chemically burned eyes in which the fellow eye has also sustained significant injury, clearly limbal autotransplantation is not an option. However, the use of fresh unmatched donor limbal tissue for limbal allograft transplantation has been reported $\mathrm{d}^{12,13}$ and one of us has performed two such procedures (unpublished data). The harvesting of donor limbal tissue from cadaveric eyes is technically very challenging. There is no data on whether limbal stem cells survive the tissue culture process and in fresh eyes the quality of the tissue is necessarily uncertain. Post-operatively, in such a vascular recipient bed, and one in which antigen presenting cells are known to be present in high concentrations, ${ }^{14}$ it is to be expected that rejection phenomena will be observed, although the authors report that the use of oral cyclosporin in this series seems to allow a high chance of a successful outcome. Nevertheless, the attendant risks of systemic immunosuppression are considerable. The use of donor limbal tissue from live related donors is also a possibility, but unless the prospective donor should happen to have an amblyopic eye, is arguably not justifiable. In our opinion the above considerations presently justify the use of autotransplant procedures where practicable.

In the longer term, tissue culture techniques offer the hope that it may prove possible to culture human limbal stem cells, such that surgical transplantation may eventually be rendered unnecessary and replaced by less invasive means of repopulating the limbus with healthy stem cells. Until such time, limbal autotransplantation has a major role to play in the rehabilitation of the unilateral, severely chemically injured eye.

Key words: Ocular alkali burn, Limbal autograft, Penetrating keratoplasty.

\section{REFERENCES}

1. Roper-Hall MJ. Thermal and chemical burns [of the eye]. Trans Ophthalmol Soc UK 1965;85:631-46.

2. Hughes WF Jr. Alkali burns of the eye. I. Review of the literature and summary of present knowledge. Arch Ophthalmol 1946;36:189-214.

3. Pfister RR, Koski J. Chemical burns of the eye. Ophthalmology 1983;90:1246-53.

4. Kenyon KR, Tseng SCG. Limbal autograft transplantation for ocular surface disorders. Ophthalmology 1989;96:709-23.

5. Mashima Y, Yamada M, Yamada H, Tsunoda K, Arimoto M. Limbal autograft transplantations for chronic ocular surface failures. Jpn J Clin Ophthalmol 1993:47:607-10.

6. Copeland RR Jr, Char DH. Limbal autograft reconstruction after conjunctival squamous cell carcinoma. Am J Ophthalmol 1990;110:412-5.

7. Kruse FE, Koch JM, Klein U, Rohrschneider K, Volcker HE, Waubke TN. The importance of limbal stem cells for the therapy of chemical burns. Ger J Ophthalmol 1993;2:289.

8. Jenkins C, Tuft S, Liu C, Buckley R. Limbal transplantation in the management of chronic contact lens associated keratopathy. Eye 1993;7:629-33.

9. Brown SI, Bloomfield SE, Pearce DB. A follow-up report on transplantation of the alkali burned cornea. Am J Ophthalmol 1974;77:538-42.

10. Kramer SG. Late numerical grading of alkali burns to determine keratoplasty prognosis. Trans Am Ophthalmol Soc 1983;81:97-106.

11. Tseng SCG, Tsai RJF. Limbal transplantation for ocular surface reconstruction: a review. Fortschr Ophthalmol 1990;88:236-42.

12. Tsai RJF, Tseng SCG. Human allograft limbal transplantation for corneal surface reconstruction. Cornea 1994;13:389-400.

13. Coster DJ. Influences on the development of corneal transplantation. Eye 1994;8:1-11.

14. Whitsett CF, Stulting RD. The distribution of HLA antigens on human corneal tissue. Invest Ophthalmol Vis Sci 1984;25:519-24. 